BLS 32, No 1 2006. DOI: http://dx.doi.org/10.3765/bls.v32i1.3435 (published by the Berkeley Linguistics Society and the Linguistic Society of America)

\title{
Verb Second, Subject Clitics, and Impersonals in Surmiran (Rumantsch)
}

\author{
STEPHEN R. ANDERSON \\ Yale University
}

Verb-second is a popular topic in the syntactic literature, but most of the discussion of this construction has centered on languages of the Germanic family. ${ }^{1}$ Some syntacticians have also discussed Verb-second in Romance, primarily on the basis of older stages of the modern languages which are no longer available for direct examination.

The only modern Romance language which appears to display Verb-second in a robust form is Rumantsch, and the present paper is devoted primarily to one form of that language, Surmiran. This language is described in a normative grammar (Signorell et al. 1987) as well as in older work such as that of Grisch (1939). Haiman and Benincà (1992) provide a general survey of Rumantsch in its various forms, including its (controversial) relation to Dolomitic Ladin and Friulian within a larger "Rhaeto-Romance" unit, though their description is descriptively limited with regard to Surmiran.

After a brief description of the external situation of Surmiran in section 0 , the basic structure of clauses is described in section 1 . Central to an understanding of Verb-second in the language is the Inversion construction discussed in sections 1.1 and 1.2, and the set of post-verbal subject clitics that can appear if the verb and its subject are inverted. Section 2 discusses an element (ins) which at first glance appears to be merely an impersonal subject pronoun, comparable to French on or German man, but which turns out to have a more complex analysis than this. Section 3 concludes that the evidence of sentences with ins representing the subject,

\footnotetext{
1 This work was supported in part by NSF award \#BCS-0418410 to Yale University. The analysis here is an extended and partially revised version of that presented in Anderson (2005), an earlier version of which appeared as Anderson (2004). I am greatly indebted to my friends in Savognin and Salouf who have provided data for this study, especially Petra Uffer, Ursus Baltermia and Reto Capeder. Naturally, neither they nor the audiences at BLS and other venues (Melbourne, Yale, Stoney Brook and the University of Massachusetts) where I have received valuable comments on this material are responsible for errors of interpretation or analysis on my part.
} 
together with some additional facts, show that "Verb-second" is not in fact an accurate description of Surmiran, and compares this language with other Verb-second languages.

\section{The Language}

The Rumantsch languages of Switzerland are spoken by approximately 60,000 people, most of whom live in the canton of Graubünden in the southeast of the country. Rumantsch is one of the four official national languages, though this should not be taken to imply a status equal in significant respects to French, German or Italian except in very specific localities within Graubünden. There are five recognized standards (Surselvan, Sutsilvan, Surmiran, Puter and Vallader), each with its own history, although the actual degree of dialect diversity is considerably greater than this. In addition, an artificial pan-dialectal standard known as Rumantsch Grischun has been widely promoted in recent years as a medium of education and communication, though this language lacks a community of native speakers, at least at present.

Surmiran is (together with Sutsilvan, the most marginal form of Swiss Rumantsch) a "central Rumantsch" language, and has about 3,000 speakers. It is still being learned by children, and is taught in local elementary schools (though it is being replaced in this function by Rumantsch Grischun in many areas). Essentially all Surmiran speakers are (at least) bilingual in German, and in Italian as well in some areas.

Surmeir, where Surmiran is spoken, includes the valley of the Gelgia leading from around Tiefenkastel up to the Julia Pass (a major route to the Engadine) and several adjacent valleys. Much discussion in the literature has focused on the dialect of Bergün (Bravuogn in Rumantsch). This, as well as the dialect of Vaz, is actually quite divergent from the normative standard of Signorell et al. (1987), which is based on the speech of the region around Savognin. The present paper is based on this latter form of the language, as spoken in Savognin and Salouf (a village of about 200 people, of whom $85 \%$ are Rumantsch speakers, the highest proportion in the country).

\section{Clause Structure}

I will assume without argument that the basic word order of Surmiran clauses is SVO, as exemplified in (1).

\section{(1) Ursus discorra rumantsch stupent Ursus speaks.3SG Rumantsch excellently Ursus speaks Rumantsch very well}

Non-subjects can, however, appear freely in initial position. As illustrated in (2), when this happens the subject appears after the finite (main or auxiliary) verb. 
Verb Second, Subject Clitics, and Impersonals in Surmiran (Rumantsch)

a. Rumantsch discorra Ursus stupent Rumantsch speaks.3sG Ursus excellently Ursus speaks Rumantsch very well

b. Stupent discorra Ursus rumantsch excellently speaks.3SG Ursus Rumantsch Ursus speaks Rumantsch very well

When the subject is inverted with the finite verb, the verb can be accompanied by a clitic element referring to the subject, as in sentence (3a). Such a clitic is not possible, however, when Inversion has not taken place, as in (3b).

a. Rumantsch discorra='l Ursus stupent Rumantsch speaks.3SG-3SGM Ursus excellently Ursus speaks Rumantsch very well

b. *Ursus discorra='l rumantsch stupent Ursus speaks.3SG-3SGM Rumantsch excellently (Ursus speaks Rumantsch very well)

A table of the subject clitic elements in provided in (4). It is beyond the scope of the present paper to justify the designation of these as "clitics," though there is some limited discussion of that matter in Anderson (2004).

\begin{tabular}{l|l} 
Person/Number(/Gender) & Subject clitic \\
\cline { 1 - 2 } $1 \mathrm{sg}$ & $=\mathbf{a}$ \\
$2 \mathrm{sg}$ & $=\mathbf{t}$ \\
3 sg masc. & $=$ 'l \\
3sg fem. & $=$ 'la \\
3 sg impersonal & $=(\mathbf{i}) \mathbf{g l}$ \\
$1 \mathrm{pl}$ & $=\mathbf{s}(\mathbf{a})$ \\
$2 \mathrm{pl}$ & $\emptyset$ \\
$3 \mathrm{pl} \mathrm{masc/fem}$ & $=\mathbf{i g l}$
\end{tabular}

When a non-subject occupies initial position, and the verb is accompanied by a subject clitic from the set in (4), this sanctions a phonetically null subject, as in (5).

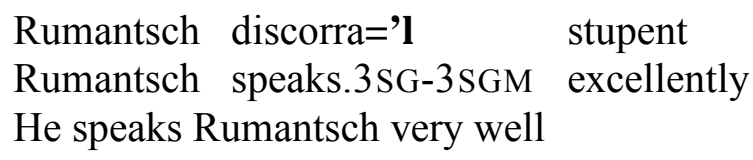

Surmiran is not in general a PRO-drop language: that is, null subjects are not allowed in the absence of a subject clitic, as shown by the ungrammaticality of sentences like (6). 


$$
\begin{aligned}
& \text { a.*Discorra rumantsch stupent } \\
& \text { speaks.3SG Rumantsch excellently } \\
& \text { (He speaks Rumantsch very well) } \\
& \text { b.*Rumantsch discorra stupent } \\
& \text { Rumantsch speaks.3SG excellently } \\
& \text { (He speaks Rumantsch very well) }
\end{aligned}
$$

Just as with the third person subjects illustrated above, first and second person subjects cannot be phonetically null (or omitted) except in the presence of a subject clitic, though the fact that the second person plural clitic is itself null partially obscures this fact. First person examples are given in (7).
a. Ia $/ * \emptyset$ discor mal rumantsch
(I) speak.1 SG badly Rumantsch
I speak Rumantsch badly
b. Rumantsch discor ia/*ø mal Rumantsch speak.1SG (I) badly I speak Rumantsch badly
c. Rumantsch discorr=a (ia) mal
Rumantsch speak.1SG-1SG I badly I (I) speak Rumantsch badly

In all persons, the presence of an overt inverted subject together with a subject clitic lends a contrastive or emphatic force to the sentence.

Surmiran also has a full set of object pronominal clitics, which behave in ways that are largely unsurprising for a Romance language. Some examples below will contain clitics of this type, but space considerations preclude a full analysis here.

\subsection{The Inversion Construction}

Against this general background, let us take a closer look at the Inversion construction. Among the non-subjects that can trigger this by appearing in initial position are argument DPs, PPs, participial phrases, entire clauses, etc., as illustrated in part in $(8)$. the living room has.3SG Ursus cleaned well Ursus cleaned the living room well
a. La steiva ò Ursus nattagea bagn
b. Tar igl gi da Rummy vala igl joker adegna in the game of rummy is.worth.3SG the joker always 25 puncts 25 points

In the game of rummy, the joker is always worth 25 points 
Verb Second, Subject Clitics, and Impersonals in Surmiran (Rumantsch)
c. Giond ier
a spass ò
Ursus scuntro Ladina
going yesterday for a walk has.3SG Ursus met Ladina
While walking yesterday, Ursus met Ladina

Among the variations on this theme that are worth noting is the possibility of having a bare past participle appear alone in initial position, as in the sentences in (9). When this happens, the participle cannot be accompanied by its object (if the verb is transitive) or by other complements. The only exception is certain short, common manner adverbs (such as mal 'badly'), which some speakers accept in sentences like (9e). This complex of possibilities is reminiscent of the construction known as Stylistic Fronting in Icelandic and other Scandinavian languages.
a. Maglea va
ia en traclo cun caschiel eaten have.1SG I a sandwich with cheese I ate a cheese sandwich
b. *Maglea en traclo cun caschiel va ia eaten a sandwich with cheese have.1SG I
c. La notg passada ò Gion durmia mal last night has.3SG John slept badly Last night John slept badly

d. Durmia ò Gion mal la notg passada slept has.3SG John badly last night John slept badly last night
e. (??)Durmia mal ò Gion la notg passada slept badly has.3SG John last night

Another interesting possibility is that of having an infinitive in initial position, followed by a finite form of the same verb. As with the participle construction in (9), the fronted infinitive cannot be accompanied by complements. These facts are illustrated in (10).
a. Cantar canta='l Ursus ena canzung to.sing sings.3sG-3SG.M. Ursus a song Ursus is singing a song
b. *antar ena canzung canta='l Ursus to.sing a song sings.3SG-3 SG.M Ursus

This construction is again reminiscent of one found in other languages, such as the topicalized infinitives in Breton (Anderson 1981). Unlike Breton, however, Surmiran doubles the verb by a finite form of the same verb, rather than with a finite form of a dummy 'light' verb such as far 'do' as in the ungrammatical (11). 
(11) *screiver fatsch ia en codesch
to-write do-1sg I a book

For some (but not all) speakers, the construction in (10) is only possible with synthetic forms of the verb, and not with periphrastic forms. This contrast is illustrated in (12).
a. Cantar cantava='l
Ursus bagn to.sing sang.3SGIMPERF-3SG Ursus well Ursus was singing well
b. */?Cantar ò='l canto Ursus bagn to.sing has $3 \mathrm{SG}-3 \mathrm{SGM}$ sung Ursus well Ursus sang well

While constituents of a variety of types can appear initially, there is a limit of one such element in preverbal position. Sentences such as (13), in which the preverbal material does not correspond to a single constituent, are thus not possible.

$$
\begin{array}{llllll}
\text { *Ier } & \text { la } & \text { steiva } & \text { ò } & \text { Ursus } & \text { nattagea } \\
\text { Yesterday } & \text { the } & \text { living room } & \text { has.3 SG } & \text { Ursus } & \text { cleaned }
\end{array}
$$

Finally, it is important to note that the verb in the Inversion construction is accompanied by any and all clitic elements (in addition to a subject clitic, if present) that would appear with it in uninverted sentences, as illustrated in (14).
a. Cleramaintg n'=ò='l
Ursus betg savia
chegl
Obviously NEG-has.3SG-3SG.M. Ursus not known that

Obviously Ursus didn't know that
b. Ier seira n'=ans=ò Maria betg telefono Yesterday evening NEG-1PL-has.3SG Maria not phoned Yesterday evening Maria didn't telephone us

In developing an analysis of the facts just reviewed, I propose to start from the "VP-internal subject" hypothesis, on which the basic subject position is that of the Specifier of VP. Assume further that the inflectional properties of the clause are realized on a verb which is head of IP. In a basic declarative clause with no (nonsubject) topic or focus element in initial position, there is no reason to assume a structural distinction between IP and VP, so I will adopt a view of phrase structure that allows me to say this. On that picture, the structure of sentence (1) above is as in (15). 


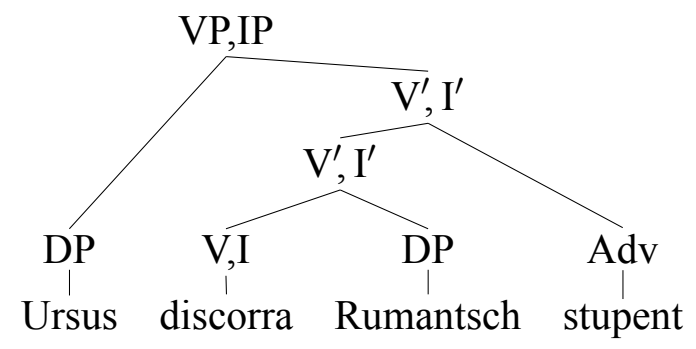

Where an initial non-subject position is required, I assume that this is $\operatorname{Spec}(\mathrm{IP})$. Since the Spec(IP) is no longer the same as Spec(VP) (the basic subject position), an additional layer of structure is required to distinguish IP from VP. In such a structure, some constituent of the core clause (the VP) is displaced to the Spec(IP) position. ${ }^{2}$ The verb must also be displaced from the head position within VP to the I head position in the matrix IP; this is presumably driven by the fact that it is only a verb in the head of IP that will acquire the clause's inflectional features. A sentence like (2a) is thus assigned the structure in (16), with the two displacements just noted indicated by dashed arrows.

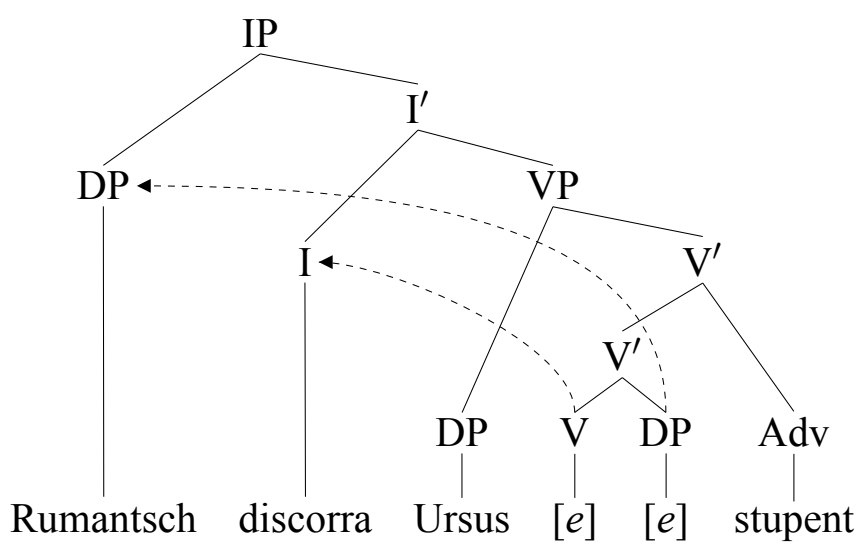

Note now that in a structure like (16) the finite verb (in I), which agrees with the subject, C-commands the basic subject position (Spec(VP)). This will be true precisely in the Inversion construction of which (16) is an instance, and I propose that it is this $\mathrm{C}$-command relation between the agreeing verb and its subject that sanctions the presence of a clitic from the set in (4).

If the subject clitics themselves (as opposed to simple verbal agreement) are potentially referential, we can then say that a Binding relation exists between such a referential subject clitic and the subject DP position which it governs, and that this is what sanctions a null pronominal (pro) in subject position in the presence of such a clitic. This is all part of a larger theory of agreement, clitics, and doubling

${ }^{2}$ Sentence-initial non-subjects are presumably assigned a discourse function such as Topic or Focus, and it is this discourse role that motivates their displacement. I have no analysis to offer at this point of the precise discourse-structure considerations at work here, and will simply assume that there is some required interpretation associated with sentence-initial position. 
relations which is developed in Anderson (2005), to which the reader is referred for further details and discussion.

\subsection{Inversion in Other Clause Types}

Inversion in Surmiran is not limited to declarative main clauses. For pragmatic reasons associated with the interpretation of non-subject material in initial position, such constituents are rare in subordinate clauses, but when they occur, they trigger Inversion as in the sentences of (17).

a. Cartez tg'igl settember turnan=s

believe.2PL that-ART September return.SBJNCTVE.1PL-1PL

ainten chel hotel

in this hotel

Do you think in September we'll come back to this hotel?

b. Ia pains tgi dultschems vegia

I think.1SG that sweets have.SBJNCTVE.3SG

Corinna gugent

Corinna gladly

I think Corinna likes sweets

When question words are fronted, they also trigger Inversion as in (18).

a. Tge ò='la (Ladina) cumpro?

what has.3SG-3SG.F. Ladina bought

What did Ladina/she buy?

b. Cura ò='la (Ladina) cumpro en auto?

when has.3SG3SG.F Ladina a car

When did Ladina/she buy a car?

c. Igl auto da tgi ò='la (Ladina) cumpro?

the car of whom has.3SG-3SG.F. Ladina bought

Whose car did Ladina/she buy?

On the other hand, when the question word corresponds to the subject, Inversion would result in no change of word order. The fact that subject clitics are impossible when the subject is questioned, as shown in (19), while questions involving nonsubjects do permit clitics (cf. (18)), suggests that in fact no Inversion occurs in this case.

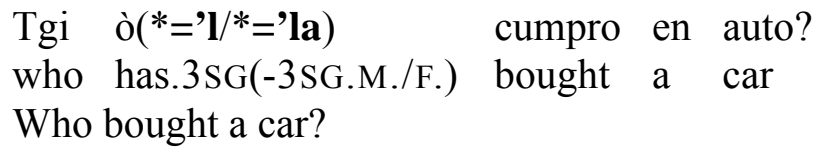


Verb Second, Subject Clitics, and Impersonals in Surmiran (Rumantsch)

When the question word is extracted from an embedded clause, that clause preserves the basic order, and it is the matrix clause that displays Inversion, as in (20).

(20) Tge manegias te tgi Ladina vegia $(*=\mathbf{l a})$

what think.2SG you that Ladina have.SBJNCTVE. $3 \mathrm{SG}\left({ }^{*}-3 \mathrm{SG}\right.$. F. $)$

cumpro?

bought

What do you think that Ladina bought?

Inversion is also characteristic of yes/no questions, although in this construction there is no (overt) sentence-initial non-subject. The uniformity of this structure with that of other instances of Inversion is confirmed by the presence of subject clitics in sentences like the last two examples in (21).

$\begin{array}{lll}\text { a. E } & \text { igl viadi sto tger? } \\ \text { is.3SG } & \text { the trip been expensive }\end{array}$

Was the trip expensive?

b. Ast er te gost da neir?

have.2SG also you desire to come

Do you want to come too?

c. Lain=sa (nous) eir cugl tren? want.1PL-1PL we go with.the train

Do we want to take the train?

d. $\mathbf{A t}=\mathbf{o}=\mathbf{g l} \quad$ plaschia an Sicilia?

2SG-has.3SG-3IMPERS pleased in Sicily

Did you like Sicily?

On the other hand, Inversion does not occur in some instances where it might be expected. Subordinate clauses are commonly introduced by a complementizer tge, and we might expect this to count as a non-subject element in initial position. Sentences like (22) show that Inversion does not occur in this case.

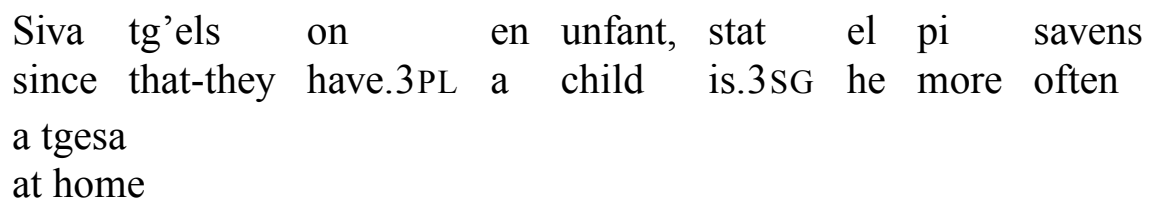

Since they have a child, he is home more often

Finally, we can note that (unlike questions) relative clauses do not in general show Inversion, regardless of what is relativized, as in (23). 
a. Igl codesch tgi è sen meisa pos=t aveir the book which is on the table can.2SG-2SG have The book which is on the table you can have

b. Igl velo tgi Ursus ò cumpro n'=è betg nov the bike which Ursus has bought NEG-is.3SG not new The bike which Ursus bought is not new

c. Igl gioven agl qual ia va scretg The youngster to.the which I have.1SG written è sto igl mies scolar is. $3 \mathrm{SG}$ been the my student

The youngster to whom I wrote was my student

d. La matta dalla qualla te ast survagnia en canaster the girl from.the which you have.2SG received a basket mareida proximamaintg marries.3SG in the near future

The girl who turned you down is getting married soon

We might expect the relative pronoun tgi to be similar to the complementizer tge in this respect, but it is more striking that even complex relative expressions such as agl qual 'to which/whom' fail to produce inverted orders (or the associated subject clitics).

Let us now consider how to incorporate these additional facts into the account of Surmiran structure developed in section 1.1. I suggested there that Inversion was associated with a structural differentiation of IP and VP forced by the need to provide a clause-initial non-subject position. From the absence of Inversion in embedded clauses introduced by tge, I conclude that such structure is not necessary to provide for this Complementizer. In fact, it is suggested in Anderson (2005) that tge does not occupy a structural position in phrase structure at all, but is rather a clitic introduced into the phonological form of embedded clauses on the basis of their character as complements. In any event, no structure above the level of VP (or IP, in the case of exceptional sentences like (17) with initial non-subjects in embedded clauses) is required to host tge.

Inversion does occur in (most) questions, so let us suppose that these are characterized by an interrogative operator $Q$, a feature of $I$. The presence of $Q$ alone characterizes yes/no questions; in content questions, the question word itself must occupy (or move to) the position of the Specifier of the I containing $Q$. To establish its scope, $Q$ must govern the entire clause (in yes/no questions) or all of it except for the question word in its specifier (for information questions).

Since $Q$ is associated with I, in order to establish its scope in yes/no questions the elaborated structure with IP distinct from VP is required, which in turn forces the verb to be displaced to the higher I, yielding Inversion. In content questions, the higher structure is again motivated when the question word is not the subject; 
the question word is displaced as required to the higher specifier position, and the verb to I, again yielding Inversion. When the question word is the subject, however, the minimal structure with $\mathrm{VP}=\mathrm{IP}$ meets all of the required conditions without elaboration. The question word, as subject, is located in the position of specifier of the head $\mathrm{I}(=\mathrm{V})$ bearing $Q$, and that element in turn governs the remainder of the clause. This accounts for the asymmetry by which Inversion is not found in content questions where the content word is the subject.

Relative clauses differ from questions, in that no operator such as $Q$ is associated with $I$ in a relative clause. The relative expression is preposed, and binds a gap within the clause. In subject relatives no word order changes are required, since the relative is already in clause initial position. In non-subject relatives, the relative expression is simply extracted and adjoined to the clause. In neither case is additional IP structure required, and as a result, none is projected, the verb remains in its base position, and the diagnostic properties of Inversion such as subject clitics do not appear.

Overall, then, I conclude that the implementation of "Verb-second" in Surmiran consists in displacing the verb from its base position as head of VP to the head of a containing IP where that is distinct. From this position, it C-commands the basic subject position, thus sanctioning the presence of a subject clitic. When such a clitic is present and interpreted as referential, this in turn sanctions phonologically null pro in subject position.

\section{The Syntax of ins}

Interesting additional light is shed on the nature of Verb-second in Surmiran by a consideration of the syntax of the element ins. This generally appears in lieu of an overt subject, with impersonal interpretation similar to that of German man or French on in sentences like (24).

Ins na pò betg eir quant spert tg'ins vot
ins NEG can-3sg not go as fast that-ins wants.3SG
sen las autostradas svizras
on the freeways Swiss

You can't go however fast you want on the Swiss freeways

Like impersonals in many other languages, ins cannot represent a non-subject argument, as illustrated in (25).

a. *Igls pulizists na pon betg veir ins da lò the policemen NEG can.3SG not see ins from there The police can't see one from there 
b. *Mintgign digls guids ò la sia moda each of.the guides has.3SG the his way

da trattar cun ins of to-deal with ins

Each of the guides has his way of dealing with one

Although superficially just a sort of indefinite pronoun with a restriction to subject position, ins does not act like other arguments (full DPs or pronominals) occupying subject position. In particular, it does not undergo Inversion with the verb when a non-subject is clause initial, as in (26).

a. Dalla derivanza digls rets ins so tant scu of.the origin of.the Rhaeti ins know.3SG so-much as navot nothing

Of the origins of the Rhaeti ${ }^{3}$ we know almost nothing.

b. D'anviern ins pò eir sur tot igls pass cun auto In winter ins can.3SG go over all the passes with car In the winter you can go over all of the passes by car

Similarly, ins fails to invert in questions of either the yes/no or the content type, as illustrated in (27).

a. Ins viagia pi bagn cugl tren $u$ ins travels.3SG more good with-the train or cugl auto sch'ins fò viadis pi lungs? with-the car if-ins makes trips more long Does one travel better by train or by car when making longer trips?

b. Tge meis digl onn ins dovra pneus what month of.the year ins needs.3SG tires d'anviern aint igl Grischun? of-winter in the Graubünden

What month of the year do you need winter tires in Graubünden?

Although the position of ins immediately before the verb does not change in contexts such as (26) and (27) where we would expect Inversion, we do find another diagnostic of Inversion in these sentences. Specifically, a subject clitic $=(\boldsymbol{i}) \boldsymbol{g} \boldsymbol{l}$ can appear in ins-sentences precisely when we would expect to find Inversion: in the presence of an initial non-subject as in (28a), in yes/no questions like (28b), and in content questions like (28c). This is the same clitic that appears in Inversion structures with other impersonals, such as existentials and weather verbs.

${ }^{3}$ Early indigenous people of the Rumantsch area. 
Verb Second, Subject Clitics, and Impersonals in Surmiran (Rumantsch)

a. Ainten chell'ustareia ins (na) magl=igl betg in this-inn ins neg= eat.3 SG-3IMPERS not

schi bagn, on=igl detg

so well have.3PL-3PL said

In this inn you don't eat so well, they said

b. Ins pò=gl fimar cò?

ins can.3SG-3IMPERS to-smoke here

Can you smoke here?

c. Quant dei ins $\mathbf{0}=\mathbf{g l}$ cugl auto anfignen

how long ins has.3SG-3IMPERS with the car to

sensom igl pass?

top the pass

How long is it by car to the top of the pass?

Etymologically, ins is derived from Latin UNUS like many other Romance impersonals. Its behavior, however, is not simply that of a pronoun. Rather, it seems more like the impersonal structures of Spanish or Italian in (29), which are based on a verbal clitic (in those languages, one identical with the third person reflexive) in association with an otherwise empty subject position, presumably occupied by a phonologically null pronominal of some sort.

(29) Spanish: En México se trabaja mucho in Mexico se works.3SG much In Mexico one works a lot

\section{Italian: $\mathrm{Si}$ lavora sempre troppo \\ si works.3SG always too much \\ One always works too much}

Another parallel is with certain impersonal verbal forms in Celtic. McCloskey (2005) has recently shown that the "autonomous" form of the verb in Irish, illustrated by example (30a), occurs with a phonologically null subject $\mathrm{PRO}_{\mathrm{ARB}}$ with the semantics of an arbitrary pronoun. A similar analysis was proposed in (Anderson 1982) for the Breton verbal form in (30b).

a. (Irish:) Tugtar 'madadh uisce' go minic ar an give.PRES.AUT dog water often on the dobharchú otter

The otter is often called a water-dog

b. (Breton:) An eil pred a anver merenn the second meal PRT call.PRES.AUT lunch The second meal is called lunch 
In these respects, Surmiran ins differs from the corresponding elements in other forms of Rumantsch, as illustrated in (31).

Vallader: Passand tras il desert as= chatta
Passing across the desert 3SGREF finds.3SG
qualchevoutas skelets
sometimes skeletons
Crossing the desert, one sometimes finds skeletons
Puter: Passand tres il desert chatta ü qualchevoutas
passing across the desert finds.3SG man sometimes
skelets
skeletons
Crossing the desert, one sometimes finds skeletons
Surselvan: Nua ein ins cun la lavur? Ins ei
where is.3SG ins with the work ins is.3SG at-the
fin. Na, alla fin ein ins mai.
end no at-the end is.3SG ins never
Where are we with the job? We're finished. No, we're never
finished.

In Vallader, impersonals are formed using a third person singular reflexive verbal clitic, similar to the Spanish and Italian constructions of (29). In Puter, this construction is possible, as well as one with $\ddot{u} n$ in subject position. Like Surmiran ins, this is a reflex of Latin UNUS, but unlike ins, it behaves as a normal pronoun and inverts with the verb when appropriate. In Surselvan, we have an element ins that is phonetically like the Surmiran form, but which (like Puter $\ddot{u} n$ ) acts like a normal pronoun. Finally, in Sutsilvan (which will be exemplified later below), we have ign, another reflex of UNUS which again acts like a normal pronoun.

It should be noted that some Surmiran speakers do accept sentences in which ins has inverted with the verb as in (32). They report, however, that this order "sounds like German." Since nearly all speakers of Surmiran are bilingual in German, as noted above, this influence is not hard to account for. What is notable about it, indeed, is the fact that this order is still felt as foreign to Surmiran.

$$
\begin{aligned}
& \text { \#Chegl dei ins dapertot } \\
& \text { That says.3SG ins everywhere } \\
& \text { That they say everywhere (OK, but 'sounds like German') }
\end{aligned}
$$

Since ins comes historically from UNUS used pronominally, it ought to behave as a pronoun. So why does it display the strange behavior it does? A clue is furnished by the fact that in at least one older description, Grisch (1939) transcribes 
ins as homophonous with ans=, the first person plural object clitic. And indeed, in rapid speech for many speakers, the two may not be distinct phonetically.

A relation between impersonals and first person plural forms is known from both French and Italian. As illustrated in (33) impersonal forms in these languages can be used with first person plural reference.

$$
\begin{aligned}
& \text { French: Nous, on fait } \begin{array}{l}
\text { pas ça ici } \\
\text { we on does.3SG not that here } \\
\text { We don't do that here }
\end{array} \\
& \text { Italian: } \\
& \mathrm{Si} \text { è } \\
& \text { si is.3 } \mathrm{SG} \text { happy. } \mathrm{PL} \text { when } 1 \mathrm{PL} \text { write.3PL } \\
& \text { We are happy when they write to us (Burzio (1992)) }
\end{aligned}
$$

Indeed, one occasionally finds Surmiran sentences such as (34) in which impersonal ins must be interpreted as having first person plural reference.

Scu indigen ins sa renda savens betg ple chint digls
As natives ins REFL take often not much account of.the
prievels da nossa nateira.
dangers of our nature

As locals, we often don't pay attention to the dangers in our natural setting.

It is not implausible to suggest, then, that a relation between impersonals and first person plural forms might have some role to play in the development of ins. This is not to suggest that they are the same element in the modern language: for one thing, they are phonetically distinct (as [Ins] $v s$. [əns]) outside of rapid speech. In addition, although both act as if they were clitics attached at the left of the finite verb, they occur in different positions with respect to other clitics, as shown in (35).

$$
\begin{aligned}
& \mathrm{Da} \text { lò ins } \mathbf{n}^{\prime}=\mathbf{a n s}=\text { vei }=\mathbf{g l} \text { betg cleramaintg } \\
& \text { from there ins NEG-1PL sees.3SG-3SG not clearly } \\
& \text { From there one doesn't see us clearly }
\end{aligned}
$$

Furthermore, in periphrastic modal constructions such as (36), ins always precedes the finite verb, while ans=, like other object clitics, can attach to the infinitive.
a. El vot
ans $=$ tarmetter dumang ena factura He wants.3SG 1PL to.send tomorrow a bill He wants to send us a bill tomorrow
b. Mintgatant ins stò(=gl) spitgier en po often ins must.3SG(-3IMPERS) wait a bit Often you have to wait a bit




$\begin{array}{lllll}\text { c. } * \text { Mintgatant } & \text { stò(=gl }) & \text { ins } & \text { spitgier } & \text { en po } \\ \text { often } & \text { must.3 SG(-3IMPERS }) & \text { ins } & \text { wait } & \text { a bit } \\ \text { Often you have to wait a bit } & & & \end{array}$

What should we conclude from these facts? The behavior of ins, and in particular its failure to invert when appropriate despite evidence (from subject clitics) that the associated verb has in fact been displaced in the same way as other Inversion constructions, finds a natural explanation if we say that it has been re-analyzed as a special sort of preverbal clitic. I propose, then, that sentences with ins have a structure parallel to that of the Spanish and Italian examples in (29), with the subject position occupied by phonetically null $\mathrm{PRO}_{\mathrm{ARB}}$ and a clitic (here, ins=) attached to the verb and positioned before other clitics such as the first part of negation or an object pronominal.

Historically, I suggest that this situation arose as a result of the similarity of ins to the first person plural clitic ans=. This reanalysis was facilitated by similarities to Italian, a language in which (a) impersonal sentences involve $\mathrm{PRO}_{\mathrm{ARB}}$ as subject and a preverbal clitic, and (b) first person and impersonal reference are closely related. Given widespread familiarity with Italian on the part of Surmiran speakers, especially before the more recent expansion of German influence in Graubünden, this does not seem an implausible suggestion, though of course more historical evidence would certainly be welcome to confirm it.

If this is correct, then under conditions triggering Inversion a verb whose subject is $\mathrm{PRO}_{\mathrm{ARB}}$ is displaced from $\mathrm{V}$ to I, just like any other. It thus comes to C-command the basic subject position (containing $\mathrm{PRO}_{\mathrm{ARB}}$ ), resulting in the possible introduction of an appropriate subject clitic $(=(\mathbf{i}) \mathrm{gl})$.

\section{Verb-second in Surmiran}

What is the significance of these facts for an understanding of Verb-second in Surmiran? As a clitic, ins is attached to the finite verb, and does not alter its position with respect to that word under displacment in Inversion constructions. But that implies that the sequence 'ins +verb' is simply another instance of the verb together with its accompanying clitic(s). As a consequence, sentences like (24) have no phonetically realized element preceding the verb, and so the verb is not in fact in second position, but rather first. If, on the contrary, we were to say that ins in (24) 'counts' as filling first position, then we would be in trouble with sentences like (26), where an initial non-subject, combined with ins, would result in the verb being in third position. Since no other re-orderings occur in these cases, we have to conclude that the verb in Surmiran is not in fact required to be in second position.

In fact, there are a few other sentence types that reinforce this point. Matrix experiencer predicates ('be unhappy', 'seem', etc.) with postposed sentential subjects and clitic pronominal experiencers, have the verb together with its object clitic in sentence-initial position, as in (37). 
Verb Second, Subject Clitics, and Impersonals in Surmiran (Rumantsch)

$\begin{array}{lllll}\text { (37) } & \mathbf{A m}= & \text { displai /A me } & \text { displai(=gl) } \\ \text { 1 } \mathrm{SG} \text { displeases / to me } & \text { displeases (-3 IMPERS) } \\ \text { tgi chesta construcziun } & \text { antscheva } & \text { cugl verb } \\ \text { that this } & \text { sentence } & \text { begins } & \text { with.the verb }\end{array}$

I am unhappy that this sentence begins with the verb

Sentences of this sort are always impersonal. It is possible for them to have an initial dummy subject igl; such dummy subjects are normally obligatory in true impersonal sentences, but with a pronominal clitic representing the experiencer, need not appear. On the other hand, when the experiencer is represented by a full $\mathrm{PP}$, as in the second variant of (37), initial igl is obligatory unless the experiencer $\mathrm{PP}$ is preposed (as here), in which case we have a normal Inversion construction as evidenced by the possibility of the subject clitic. The generalization seems to be that a preverbal clitic (ins, or $\mathbf{a m =}$ in (37)) can count as "sort of" a subject, thus avoiding the need either for dummy igl or Inversion. Obviously, this suggestion remains to be made much more precise, but it seems a possible line of analysis.

For some perspective on these facts, consider their analogs in Sutsilvan, a closely related form of ("Central") Rumantsch. Here the cognate of ins, namely ign (also etymologically from Latin UNUS) behaves like a normal pronoun occupying an argument position rather than like a clitic in sentences like those of (38). As a result, it undergoes Inversion in sentences parallel to ones in Surmiran above in which Inversion does not take place.

a. Ign dastga fimar dapartut an quell'ustreia ins can.3SG to.smoke everywhere in that restaurant You can smoke anywhere in that restaurant

b. Gl'unviern san ign ir cugl auto sur tut in winter can.3SG ins to.go with the car over all igls pass the passes In the winter you can go over all of the passes by car (cf. (26b) above)

c. Quant gitg ân ign cugl auto antocen senzum igl pass? how long has ins with the car to top the pass How long is by car to the top of the pass? (cf. (28c) above)

Furthermore, impersonal experiencer sentences in Sutsilvan parallel to Surmiran examples in which the verb is initial, like the first variant of (37), always have dummy subjects as illustrated in (39). 
Stephen R. Anderson

(39)

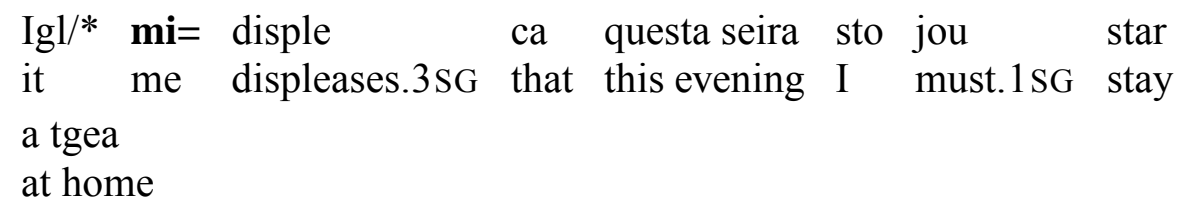

I am sorry that I have to stay home this evening

I conclude that the grammar of Sutsilvan really does constrain the verb to occur in second position, through mechanisms discussed in Anderson (2005). The same appears to be true of the other Swiss Rumantsch languages, though a demonstration of that must be left to another occasion. In Surmiran, however, the element ins was reanalyzed as a clitic, under the influence of its similarity to ans $=$ and other factors cited above. Such a reanalysis could not have taken place in Sutsilvan, since ign bears no particular resemblance to any preverbal clitic. As a result, for a significant class of sentences the Verb-second condition ceased to be true in Surmiran, and was lost from the grammar. In the modern language, the sense in which Surmiran is a "Verb-second" language is limited to the fact that Inversion occurs where it is motivated: that is, the verb is displaced from $V$ to I exactly when the clause displays IP structure distinct from that of the core VP.

There is no little irony in this: the standard story about Verb-second in German that dominates the syntax literature claims that in this language, Verb-second consists in the requirement "Displace the verb from I to C". Much of that literature treats the "second position" effect as epiphenomenal, and the required verb raising operation (which blocks under some circumstances) as primary. In Anderson (2005), however, it is argued that the best analysis of all of the Indo-European Verb-second languages (apart from Surmiran), including members of the Germanic, Celtic, and Indic families, involves explicit verb second requirements, with displacement of the verb following from these, rather than the other way around.

On this account, Surmiran works the way German is often thought to, and isn't a Verb-second language in the sense of having a second position requirement in its grammar at all. It just looks like a Verb-second language, because the effect of Inversion (which is driven by something quite different) typically has the epiphenomenal consequence of locating the verb after exactly one sentence-initial constituent.

\section{References}

Anderson, Stephen R. 1981. Topicalization in Breton. Proceedings of the Annual Meeting of the Berkeley Linguistics Society 7:27-39.

Anderson, Stephen R. 1982. Where's Morphology? Linguistic Inquiry 13:571-612. Anderson, Stephen R. 2004. Subject Clitics and Verb-second in Surmiran Rumantsch. MIT Working Papers in Linguistics 47:1-22.

Anderson, Stephen R. 2005. Aspects of the Theory of Clitics. Oxford: Oxford University Press. 
Verb Second, Subject Clitics, and Impersonals in Surmiran (Rumantsch)

Burzio, Luigi. 1992. On the Morphology of Reflexives and Impersonals. In Christiane Lauefer and Terrell Morgan, eds., Theoretical Analyses in Romance Linguistics (LSRL XIX), 399-414. Amsterdam: Benjamins.

Grisch, Mena. 1939. Die Mundart von Surmeir, Romanica Helvetica, volume 12. Paris: E. Droz.

Haiman, John, and Paola Benincà. 1992. The Rhaeto-Romance Languages. London: Routledge.

McCloskey, James. 2005. The Grammar of Autonomy in Irish. Ms., University of California, Santa Cruz.

Signorell, Faust, Wuethrich-Grisch, Mena, and Gion Pol Simeon. 1987. Normas Surmiranas. Coira: Tgesa editoura cantunala per stampats e meds d'instrucziun.

Stephen R. Anderson

Yale University

Department of Linguistics

370 Temple Street

New Haven, CT 06520-8366

sra@yale.edu 